\title{
Analisis Implementasi Media Komunikasi Berbasis IP Menggunakan Arterisk Freepbx
}

\author{
Analysis of the Implementation of IP-Based Communication Media With Arterisk \\ Freepbx
}

\author{
Bagoes Ramadhan*1, Muhamad Fatchan ${ }^{2}$, Elkin Rilvani ${ }^{3}$ \\ 1,2,3 Program Studi Teknik Informatika, Fakultas Teknik, Universitas Pelita Bangsa \\ e-mail: *1bagoesramadhan@mhs.pelitabangsa.ac.id, ${ }^{2}$ fatchan@pelitabangsa.ac.id, \\ ${ }^{3}$ elkin.rivalni@pelitabangsa.ac.id
}

\begin{abstract}
Abstrak
Voice over Internet Protocol (VoIP) merupakan teknologi yang memanfaatkan Internet Protocol untuk menyediakan komunikasi voice secara elektronis dan real-time. Unsur pembentuk VoIP adalah User agent, Proxy, Protocol dan Coder-Decoder (CODEC). Asterisk merupakan softswicth untuk mengoperasikan proxy, yang berbasis session initiation protocol (SIP). Tujuan dari penelitian ini adalah membangun server VoIP berbasis Asterisk, agar dapat dikembangkan pada penelitian selanjutnya sesuai dengan kebutuhan. Penelitian ini dilakukan pada instalasi yang sudah dibangun jaringan internet sebelumnya. Sehingga VoIP disini difungsikan sebagai pemaksimalan jaringan internet yang sudah ada tersebut untuk menekan biaya pengeluaran kebutuhan komunikasi. Layanan yang disediakan pada penelitian ini berbentuk voice dan video dengan layanan call client to server, call client to client, video call conference, video conference.
\end{abstract}

Katakunci: Voice over Internet Protocol (VoIP), Asterisk, FreePBX Session Initiation Protocol (SIP), Ubuntu 10.10

\begin{abstract}
Abstrack
Voice over Internet Protocol (VoIP) is a technology that utilizes Internet Protocol to provide voice communications electronically and real-time. VoIP forming elements are User agents, Proxy, Protocol and Coder-Decoder (CODEC). Asterisk is a softswicth for operating proxies, based on session initiation protocol (SIP). The purpose of this research is to build an Asterisk based VoIP server, so that it can be developed in subsequent research as needed. The research methodology undertaken, Broadly speaking consists of two paths, namely literature studies and experiments. This research is done on the installation that has been built internet network before. So VoIP here functioned as the maximization of the existing Internet network to reduce the cost of communication needs expenditure. The service provided in this research is in the form of voice and video with call client to server service, call client to client, video conference call, video conference.

Keywords: Voice over Internet Protocol (VoIP), Asterisk, FreePBX Session Initiation Protocol (SIP), Ubuntu 10.10
\end{abstract}

\section{PENDAHULUAN}

Perkembangan teknologi khususnya teknologi informasi membawa perunahan yang sangat mendasar bagi dunia telekomunikasi. Dalam teknologi komunikasi, komunikasi suara merupakan satu hal yang akan menjadi bagian yang sangat penting, karena saat ini komunikasi suara dianggap komunikasi yang paling praktis. Hal ini menyebabkan hadirnya teknologi pemrosesan sinyal digital yang mempunyai kemampuan modular dengan berbasis teknologi IP (Internet Protocal) yang di integerasikan antara komunikasi data dan suara. VoIP (Voice over Internet Protocol) adalah teknologi yang mampu melewatkan "panggilan suara", video dan data melalui jaringan IP[1]. Bentuk panggilan analog akan dikonversikan menjadi bentuk digital dan dijalankan sebagai data oleh intemet protokol[2]. Jaringan IP sendiri merupakan jaringan 
komunikasi data yang berbasis packed switch, sehingga kita bisa menelepon dengan menggunakan jaringan IP atau internet. Jaringan VolP dapat dibangun dengan menggunakan jaringan nirkabel dan kabel[3]. VolP memungkinkan perutean, access server dan multiservice access concentrator membawa dan mengirim suara dan fax melintasi jaringan IP.

Pada penelitian ini penulis akan mengimplementasikan sebuah media komunikasi berbasis IP untuk salah satu perusahaan E-Commerce terbesar di Indonesia yaitu Lazada Indonesia, untuk membantu meningkatkan efektivitas dan efisiensi dari segi system maintenance, user interface, cost and benefit perusahaan menggunakan system berbasis Asterisk yaitu FreePBX. Adapun tujuan dari penelitian ini adalah mengaplikasikan dan membangun komunikasi sistem telepon berbasis teknologi VoIP dilingkungan perusahaan Lazada Indonesia yang berguna untuk menekan biaya operasional perusahaan dalam hal komunikasi, lebih efektif dibandingkan harus menggunakan telepon konvensional seperti halnya menggunakan layanan dari ISP, membuat record percakapan antara customer dan customer service dan mengamankan komunikasi yang bersifat rahasia. Sistem VoIP dipilih karena dapat menghemat biaya operasional terkait dengan komunikasi suara yang dibutuhkan karena teknologi VoIP ini bersifat open source yang dapat memberikan solusi alternatif komunikasi yang lebih murah, selain itu teknologi ini juga mampu melewatkan trafik suara, video, dan data yang berbentuk paket melalui jaringan IP[4]. VoIP juga dapat digunakan untuk pada kampus dengan memanfaatkan fasilitas wifi tanpa memerlukan biaya biaya telpon maupun kuota internet di smartphone sehingga dapat mengurangi biaya operasional suatu Universitas [5].

\section{METODE PENELITIAN}

Dalam penelitian ini, akan digunakan pendekatan pengembangan sistem dengan metode Network Development Life Cycle (NDLC) untuk mengimplementasikan teknologi informasi berbasis IP menggunakan asterisk sesuai permasalahan. Adapun tahapan yang dilakukan dalam NDLC tersebut adalah:

a. Analysis

Tahap awal ini dilakukan analisa kebutuhan, analisa permasalahan yang muncul, analisa kebutuhan user dan analisa topologi jaringan yang sudah ada saat ini [6]. Bisa dibilang tahap ini adalah tahap pengumpulan data untuk mengetahui perumusan masalah dengan cara menyelesaikan masalah tersebut. Dalam hal ini mengidentifikasi system yang sedang berjalan, lalu mengerti kekurangan system tersebut dan mencoba menganalisa pengembangan system seperti apa yang cocok diterapkan dalam system tersebut

b. Design

Dari data-data yang didapat sebelumnya, tahap design ini akan membuat gambar design topologi jaringan yang akan dibangun [7], diharapkan dengan gambar ini akan memberikan gambaran seutuhnya dan kebutuhan yang ada

c. simulation protoyping

Tahapan ketiga yang akan dilakukan adalah tahapan membangun simulasi berupa prototipe sistem[8]. Penulis akan melakukan penerapan system dalam sklah kecil atau tahap uji coba pada suatu area dengan satu access spoint.

d. Implementation

Dalam implementasi penulis akan menerapkan semua yang telah direncanakan dan didesign sebelumnya. Implementasi merupakan tahapan yang menentukan dari berhasil atau gagalnya project yang akan dibangun[9], pada tahap implementasi ini penulis akan mengimplementasikan setting konfigurasi menggunakan Softphone 3CX.

e. Monitoring

Setelah implementasi tahapan monitoring merupakan tahapan yang penting, agar jaringan komputer dan komunikasi dapat berjalan sesuai dengan keiinginan dan tujuan awal dari user pada tahap awal analisa, maka perlu dilakukan kegiatan monitoring. Monitoring bisa dilakukan 
berupa pengamatan untuk memantau traffic yang berjalan dijaringan sesuai dengan semestinya[10], memantau aktifitas user, melihat Extension yang aktif pada jaringan dan melihat hasil pengukuran bandwidth pada keseluruhan jaringan

f. Management

Pada tahap management ini akan dilakukan beberapa langka pengelolahan agar system yang telah dibangun dapat berjalan sesuai dengan yang diharapkan[11]. Seperti membuat login server agar tidak sembarang orang dapat masuk ke jaringan dan melakukan backup konfigurasi, agar sewaktu-waktu terjadi hal yang dapat membuat jaringan rusak, kita dapat mengembalikan pada konfigurasi semula

Saat ini Jaringan yang berjalan pada perusahaan Lazada Indonesia menggunakan komunikasi terpusat pada PABX sebagai pesawat teleponnya yang bisa berkomunikasi antar nomor extension dan apabila ingin melakukan panggilan ke nomor diluar extension seperti hal nya yang dilakukan oleh devisi Customer Services sudah bisa dilakukan dengan bantuan operator yaitu Telkom. Permasalahan yang ada diantara lain:

a. Saat ini Lazada Indonesia masih menggunakan system telephony bawaan ISP

b. Setiap membuat 1 Extension biaya yang dikeluarkan perusahaan cukup besar

c. System telephon yang berjalan sekarang tidak memungkinkan untuk menambah wawasan teknisi IT yang ada Karena hanya mengandalkan system yang sudah jadi dari ISP.

Dalam membangun sebuah jaringan PBX baru dibutuhkan beberapa komponen diantaranya adalah Hardware dan Software. Untuk perangkat keras (Hardware) membutuhkan server, router, IP Phone, serta kabel ethernet. Sedangkan untuk software penulis akan mengggunkan softphone Zoiper sebagai pengganti IP Phone dan juga sebuah Sistem Operasi FreePBX dengan Gateway yang langsung di control melalaui IP Web Browser

\section{HASIL DAN PEMBAHASAN}

Saat ini topologi jaringan fisik yang ada di Lazada tergambar pada Gambar 1. Berdasarkan hasil survei, pengamatan dan penerapan letak 2 Server PBX perusahaan (Customer Service dan Operational Office), maka dapat di rencanakan sebuah jaringan VoIP. Perusahaan memiliki beberapa bagian di departement yang tersebar di gedung dan cabang yang berbeda.

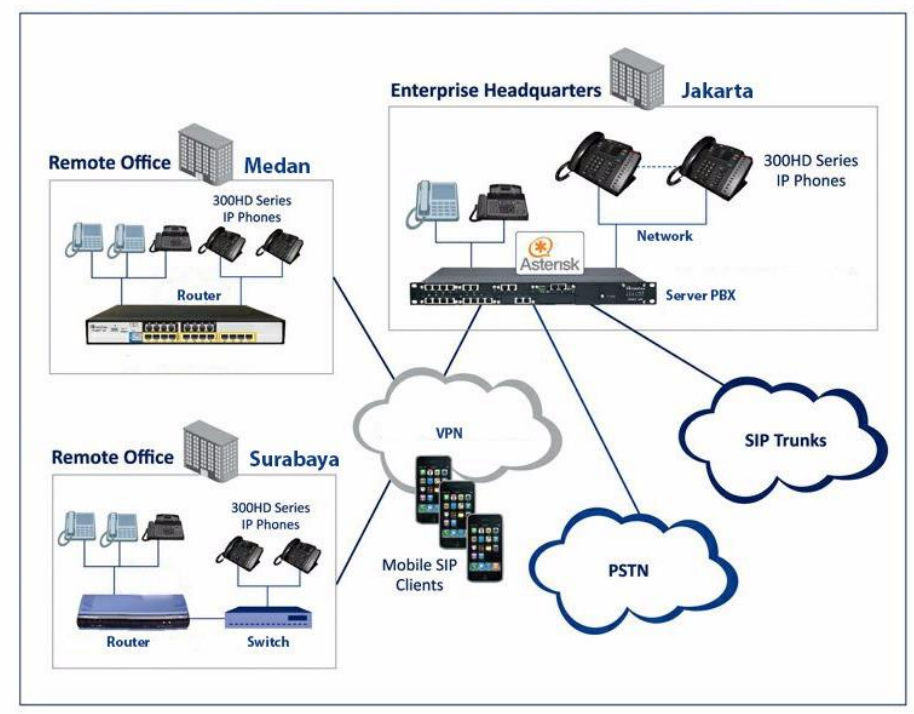

Gambar 1. Topologi jaringan fisik lazada 
Langkah awal yang dilakukan adalah melakukan instalasi FreePBX yang kemudian diteruskan dengan melakukan setting terhadap SIP trunk dan pilih yang menggunakan asterisk. Setelah semua ini terinstall maka langkah selanjutnya adalah membuat user atau nomor extension dalam melakukan konfigurasi. Pada penelitian ini akan diberikan akun pengguna dan pengaturan control sesuai dengan gambar 2 dan gambar 3.

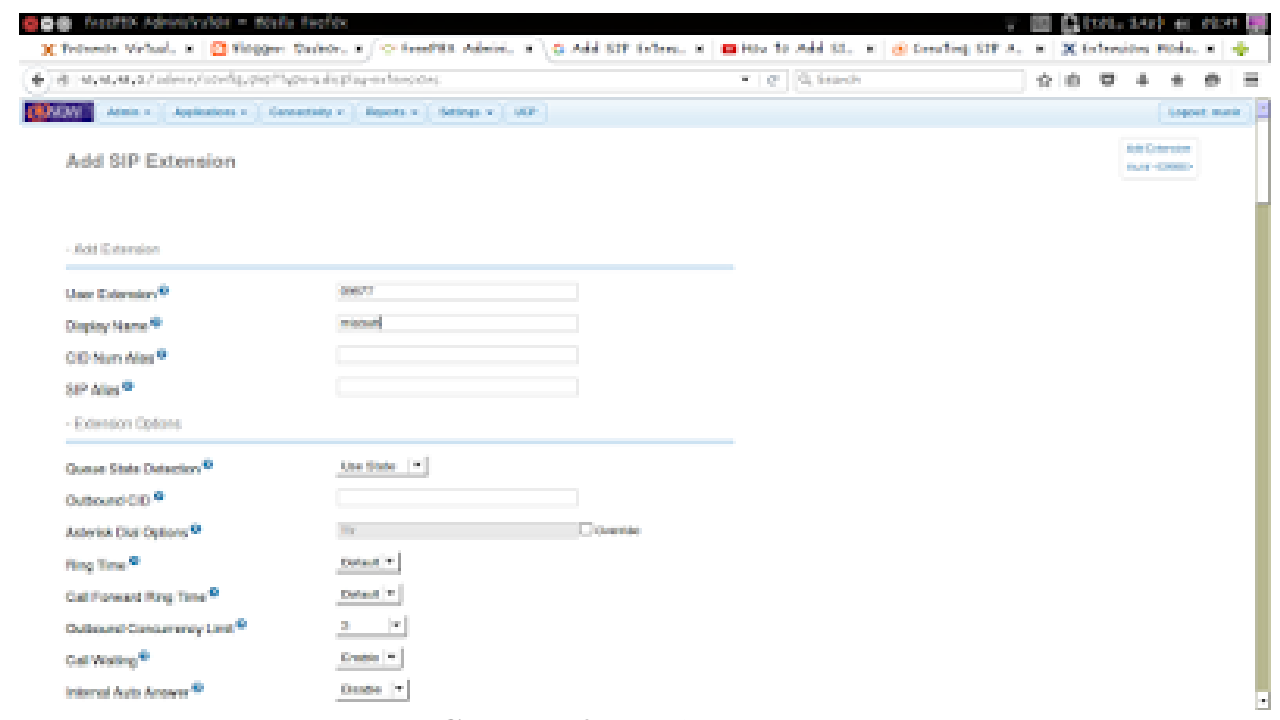

Gambar 2. Pembuatan User

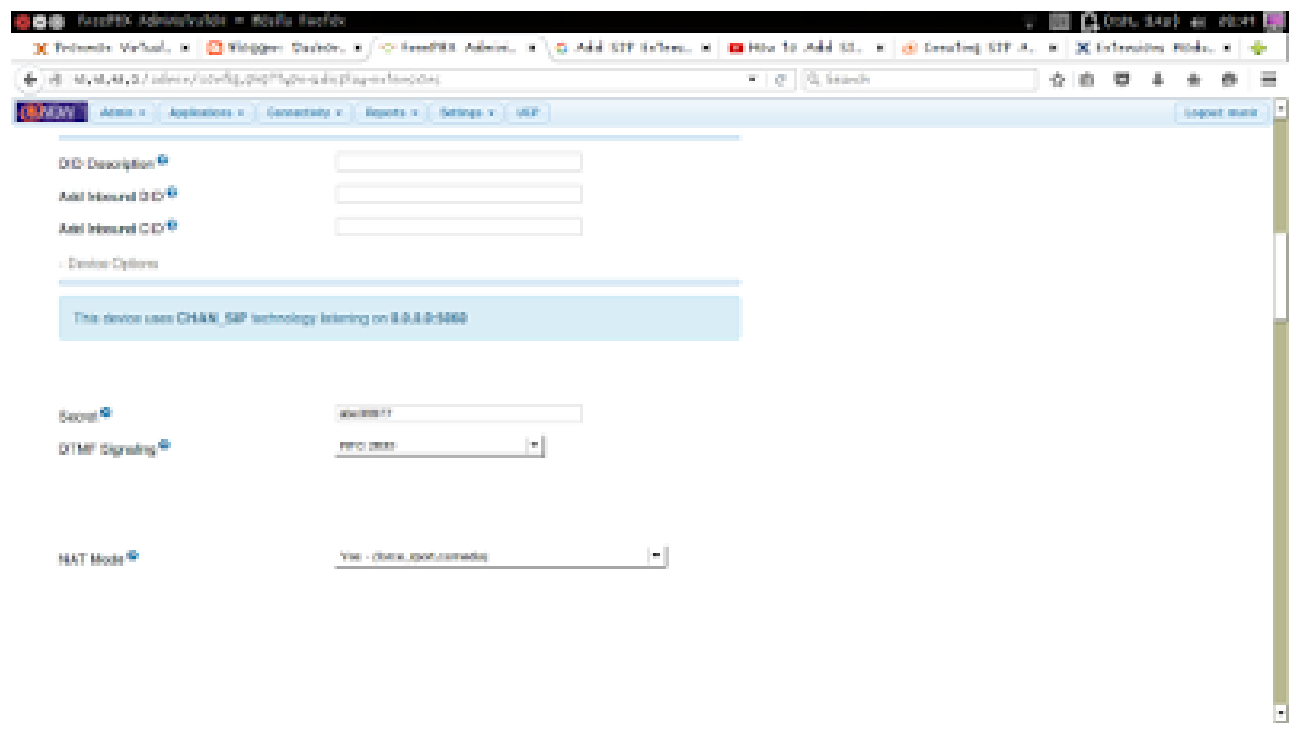

Gambar 3. Pembuatan User

Pengaturan konfigurasi pada PC Client dengan softphone

Pengaturan disini penulis menggunakan Softphone 3cx. Berikut pengaturan konfigurasi pada $P C$ Client :

a. Buka main menu 3CXPhone lalu pilih menu Accounts dan pilih New 


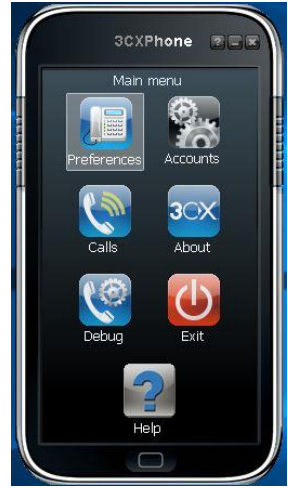

Gambar 4. Pengaturan PC Client

b. Menambah Extension dan alamat IP server.

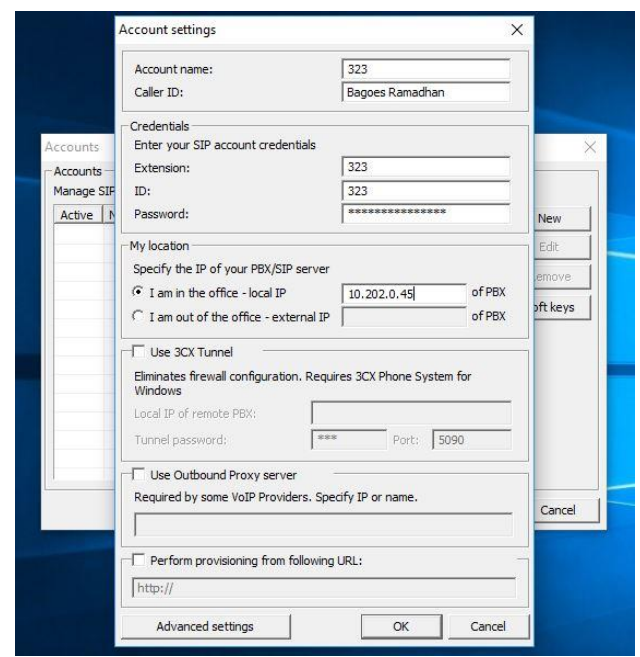

Gambar 5. Menambah Extension

\section{Melakukan Tes Panggilan Telepon}

Setelah dilakukan pengaturan pada jaringan PABX dan VoIP langkah yang terkahir adalah melakukan uji coba penggilan telepon dengan contoh sebagai berikut ini.
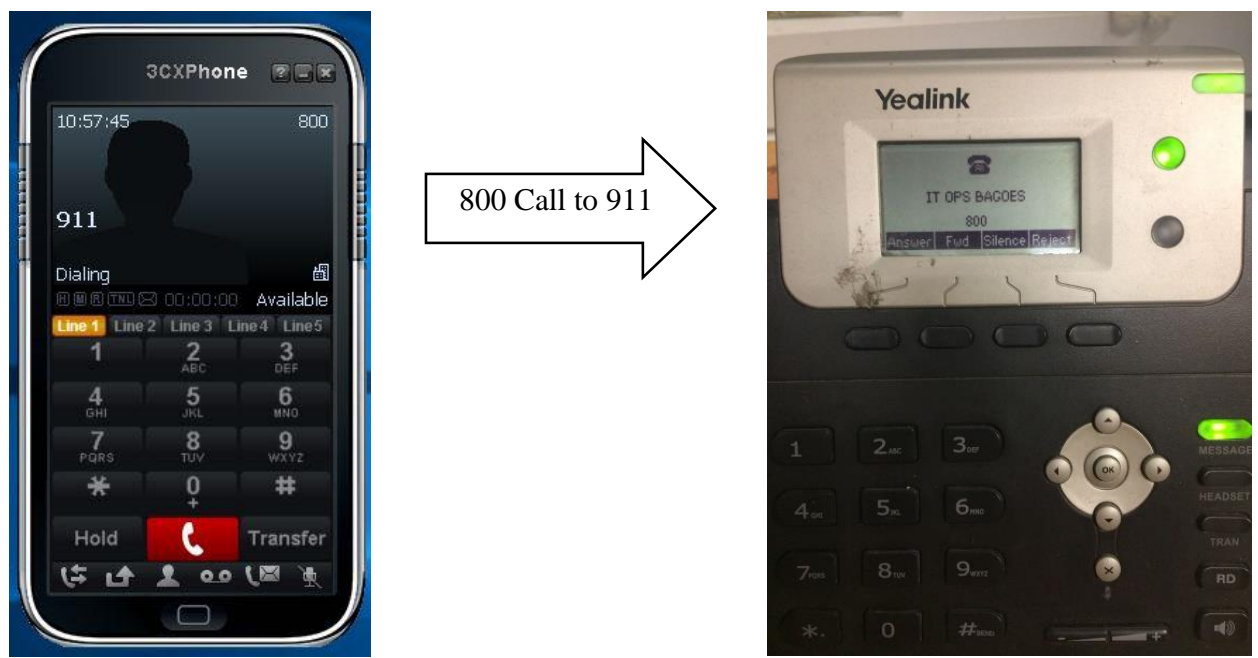

Gambar 6. Sistem Kerja VoIP Lazada Indonesia 
Dari gambar 6 bisa dijelaskan bagaimana cara berkomunikasi pesawat telepon antar kantor cabang yang berbeda lokasi dengan penjelasan sebagai berikut.

a. Saat pengguna nomor extension 800 yaitu salah satu departement yang berada di Headquarters mencoba menghubungi nomor extension 911 yang berada di remote office, hanya tinggal memasukan nomor telepon extension yang ditujukan yaitu nomor extension 911 karena sudah saling terhubung dengan Corporate IP Cloud.

b. Maka pesawat telepon dengan nomor extension 911 akan berdering menandakan berhasilnya panggilan suara dari nomor extension 800 .

c. Cara tersebut dapat dilakukan sebaliknya dengan langsung memasukan nomor extension yang dituju

\section{KESIMPULAN}

Berdasarkan hasil perancangan yang telah penulis lakukan, maka dapat ditarik kesimpulan bahwa dengan menggunakan system telephony FreePBX, akan menghemat cost yang dikeluarkan oleh perusahaan Karena system yang dikembangkan berbasis Linux yang merupakan system yang Open Source. Teknisi IT Internal perusahaan juga akan mendapatkan hak akses full $100 \%$ dikarenakan system yang berjalan sekarang merupakan system yang dibangun dari Nol dan tidak bergantung pada Vendor untuk maintenance nya.

\section{DAFTAR PUSTAKA}

[1] M. Muntahanah, R. Toyib, and I. Wardiman, "Implementasi Voice Over Internet Protocol (VOIP) Berbasis Linux (Studi Kasus SMK Negeri 03 Bengkulu)," Pseudocode, vol. 7, no. 1, pp. 41-50, 2020, doi: 10.33369/pseudocode.7.1.41-50.

[2] P. Sinuhaji, H. Wijanarko, H. Arif, and M. F. Amirul Nasrullah, "Smart Hybrid PABX Menggunakan Server Asterisk," J. Appl. Electr. Eng., vol. 3, no. 2, 2019.

[3] M. K. Br Sinuraya and B. S, "Rancang Bangun Keamanan Transfer Data VoIP Menggunakan VPN Pada Trixbox di Universitas Satya Negara Indonesia," J. Ilm. Fak. Tek. LIMIT'S, vol. 16, no. 2, 2020.

[4] W. Yunarti and R. Roestam, "Analisis dan Rancang Bangun Jaringan Komunikasi VOIP Dengan Server Briker Pada SMKN 1 Tanjung Jabung Timur," J. Manaj. Sist. Inf., vol. 3, no. 4, pp. 1272-1281, 2018.

[5] S. H. Putra and O. K. Sulaiman, "PERANCANGAN JARINGAN KOMUNIKASI VOIP ( VOICE OVER INTERNET PROTOCOL ) MENGGUNAKAN TRIXBOX PADA UNIVERSITAS ISLAM SUMATERA UTARA," CESS (Journal Comput. Eng. Syst. Sci., vol. 4, no. 2, pp. 186-190, 2019, doi: 10.24114/cess.v4i2.14075.

[6] R. Novrianda, "Implementasi authentication Captive Portal pada Wireless Local Area Network PT. Rikku Mitra Sriwijaya," Regist. J. Ilm. Teknol. Sist. Inf., vol. 4, no. 2, p. 67, 2018, doi: 10.26594/register.v4i2.1245.

[7] T. Sanjaya and D. Setiyadi, "Network Development Life Cycle (NDLC) Dalam Perancangan Jaringan Komputer Pada Rumah Shalom Mahanaim," Mhs. Bina Insa., vol. 4, no. 1, pp. 1-10, 2019, [Online]. Available: http://ejournal-binainsani.ac.id/.

[8] H. Sujadi and A. Mutaqin, "RANCANG BANGUN ARSITEKTUR JARINGAN KOMPUTER TEKNOLOGI METROPOLITAN AREA NETWORK (MAN) DENGAN MENGGUNAKAN METODE NETWORK DEVELOPMENT LIFE CYCLE (NDLC) (Studi Kasus : Universitas Majalengka)," J-Ensitec, vol. 4, no. 01, 2017, doi: 10.31949/jensitec.v4i01.682. 
[9] Y. Mulyanto and S. B. Prakoso, "RANCANG BANGUN JARINGAN KOMPUTER MENGGUNAKAN SISTEM MANAJEMEN OMADA CONTROLLER PADA INSPEKTORAT KABUPATEN SUMBAWADENGAN METODE NETWORK DEVELOPMENT LIFE CYCLE (NDLC)," (Jurnal Inform. Teknol. dan Sains, vol. 3, no. 1, pp. 301-307, 2021, doi: 10.51401/jinteks.v2i4.825.

[10] M. Iqbal and A. Zulfan, "Membangun Sistem Monitoring Keamanan Kerambah Ikan Menggunakan Sensor Gerak dan Fasilitas Smartphone untuk Nelayan di Daerah Perbatasan,” Pros. Semin. Nas. SISFOTEK, vol. 3584, pp. 153-156, 2017, [Online]. Available: https://seminar.iaii.or.id/index.php/SISFOTEK/article/view/31/23.

[11] R. Haerani and L. Z. Azhar, "Analisa Penerapan Hierarchical Tokken Buket Untuk Optimalisasi Management Bandwith Pada Server Ubuntu," J. Bumigora Inf. Technol., vol. 2, no. 2, pp. 139-148, 2020, doi: 10.30812/bite.v2i2.917. 